\title{
FOREIGN LANGUAGE LEARNING AND LOW SOCIO-ECONOMIC STATUS
}

\author{
Fruzsina Szabó, Tünde Polonyi, Kálmán Abari
}

\begin{abstract}
Foreign language learning is often the key educational objective for non-English speakers in deprived background. The command of a foreign language represents aims, possibilities and a way-out. Moreover, the term of language aptitude has always been an extremely important value to predict how fast and effectively language learners can acquire foreign languages. However, the negative meta-linguistical prognosis (I have bad ears for/bad sense of the language) easily creates a ground for self-misconception for learners, which can lead to prolonged failures in language learning as well as a learner's attitude, which will always put the blame on the difficulties or the impossibility of acquiring a foreign language. There have been countless studies on the education of pupils from disadvantaged background, however papers and research analysing foreign language learning among these pupils are scarce. In this article we hope to shed light upon current research findings, developments focusing on pupils from deprived background.
\end{abstract}

Keywords: foreign language learning, language aptitude, low socioeconomic status

\section{Introduction}

Language aptitude has always been an extremely important value to predict how fast and effectively language learners can acquire foreign languages. Everyday usage of the term language aptitude tends to differentiate between having 'good' and 'bad' aptitude. However, the negative meta-linguistical prognosis (I have bad ears for/bad sense of the language) easily creates a ground for self-misconception for learners, which can lead to prolonged failures in language learning as well as in the development of the learner's attitude, which will always put the blame on the difficulties or the impossibility of acquiring a foreign language. There have been countless studies focusing on the education and learning of pupils from disadvantaged background, however papers and research analysing foreign language learning among these pupils are scarce. In this article we hope to shed light upon current research findings, developments, the quotidian heroes of teaching and learning languages in poor environment. In prior to introducing our examination and findings, we aim to briefly highlight the disadvantageous background in Eastern Hungary, how it affects learners and then show our language aptitude examination in detail along with the methodological implications we have learnt from it.

Our research focuses on the issue of language aptitude among pupils from disadvantaged background. The original purpose of the study stemmed from the work of the Content Pedagogy Research Program of the Hungarian Academy of Sciences at Debrecen University, which has constantly been involved in developing English course-materials for tablets for schools and pupils in socially and economically deprived regions. To support research and material development, we realised the necessity of exploring the linguistic needs of pupils, as it is highly important to develop the supplementary digital coursematerial specifically designed for their needs to support their skills and help improve their learning strategies.

\section{Context and the notion of SES}

A significant example of multilingual education systems is essential to research the Nordic countries (Denmark, Finland, Norway and Sweden) because of their multilingual developments.

Low SES, or social-economic status is an indispensable term when researching the social aspects of education. SES affects all aspects of life. There have been efforts to reduce the differences in 
socioeconomic status in many countries, yet it remains an issue to be tackled. Lower levels of SES often bring about emotional, behavioural and attention-related disorders and problems (DeCarlo Santiago et al., 2011; Russell et al., 2016; Spencer et al., 2002). Adolescents are affected by depression, anxiety and various psychological problems (Newacheck et al., 2003). Ample research points to higher levels of aggression among young people from low SES backgrounds and they suffer from significant levels of discrimination (Molnar et al., 2008). Low SES affects physical health, as well. Apart from obesity, chronic stress, and high infant mortality, it can be concluded that higher rates of cardiovascular disease for adults can be experienced, based on various findings (Colhoun et al., 1998; Steptoe and Marmot, 2004). Finally, the impact on education needs to be mentioned, as well, including significantly worse linguistic skills, and increased truancy and dropout rates (Colhoun et al., 1998; Steptoe and Marmot, 2004; Zhang, 2003).

Low socio-economic status also affects the school performance of children in an indirect way (Geske and Grinfelds, 2012). Parents tend to expect their children to achieve similar schooling qualifications, thus less educated parents have fewer expectations (Kim et al., 2013). If parents experienced failure during their own school years and in their education, then they are highly likely to develop negative attitudes towards schooling and learning. They pass these aspirations and attitudes on to their children (Howard et al., 2011).

\section{The Hungarian regional characteristics}

Low social-economic status is an issue of uttermost importance in Hungary, as it determines one's family and school environment as well as the perspectives for further education and job opportunities. Hungary is a country where parental education tremendously influences the school performance of children (Szívós and Gábor, 2008). This cause-and-effect has already been noted by the Adult Literacy Survey, and it is also reflected in the country's PISA results (OECD, 2016). This influence is so significant that it diminishes the effect of other factors considered important in other countries (Lannert, 2003). The low SES impact on academic achievement is amplified by school segregation, which means that the social composition of schools varies to a great degree (Kertesi and Kézdi, 2009).

The differences in academic performance at schools have been apparent for 50 years in Hungary. The competition for further education, and especially for university admission, has gained particular importance following the political changes of the 90's. To graduate from tertiary institution is - even today - a rational decision. Secondary grammar schools are becoming increasingly selective, and, since they facilitate admission to universities, competition begins at younger and younger ages. In a competitive situation like this, students from a higher SES background have better chances. The demand for places has also prompted a bitter rivalry among schools. This has brought about a situation in which the composition of schools tends to become increasingly homogenous, while the differences between them are becoming more significant. PISA results have indicated that Hungary displays the biggest difference in academic achievement among schools, while the differences in academic achievement within schools are insignificant (OECD, 2016).

\section{Focus and Purpose of our Research}

A digital supplementary coursematerial is being developed at Debrecen University, Hungary, under the name 'Hanna'. It is written particularly for pupils from disadvantaged background, from low socioeconomic regions focusing on specific individual needs. However, as the coursematerial is monolingual (English), it can be applied in any context and circumstances regardless of the regional or national characteristics. The primary age-group is pupils aged 10-13 years old. To realise and promote our most important goals, we have decided to conduct research supporting our material-writing process to explore the individual needs of the pupils the supplementary material is written for. The overall research employs mixed methodology, a language aptitude study of pupils, focus interview with their teachers and principals, language skills testing. However, this paper only focuses on introducing the preliminary data and findings of our language aptitude testing, since this facilitates our understanding of individual needs particularly of pupils from low socio-economic background. The comparative language aptitude testing took part with the help of a control-group, a highly competitive school with $0 \%$ pupils from low socioeconomic background. 
Our research questions (1-2) and hypothesis (3-4-5) are the following:

Do pupils from low socio-economic background have different language aptitude scores?

Do pupils from higher socio-economic background have higher overall language aptitude scores?

Pupils from low SES background have lower scores in the fourth (last) component of the language aptitude test focusing on memory.

Pupils from low SES background have the same or very similar scores in the first component of the language aptitude test focusing on phonetic coding.

Pupils from higher socio-economic background have higher scores in the third component of the language aptitude test focusing on inductive thinking.

\section{Hungarian Language Aptitude Test for Young Learners}

The language aptitude test was created in Hungary by Csilla Kiss (2004) to examine the English skills and knowledge of 12-year-old pupils in South-Eastern Hungary. The test follows the pattern of Carroll's MLAT test, as it places the focus on our relatively independent "specialized" abilities. The four aspects, or "components", of language learning aptitude that Carroll identified were the following:

phonetic coding ability

grammatical sensitivity,

rote learning ability

inductive language learning ability.

Carroll looked upon these units as components, specialised abilities that form language aptitude. Research has since moved on to establish the dynamic characteristic of these components and to state that these abilities are far from being stable and can be developed (Carroll, 1962). Wen believes that research into language aptitude saw a decrease in significance and interest in the 70's and 80's as the original MLAT tasks stemmed from and were organised around rote-learning and grammatical tasks typical of audio-lingual methodology (Wen, 2012). However, research into foreign language aptitude has been experiencing revitalisation since the beginning of the 21 st century. Language aptitude has become the focus-point of predicting and establishing difficulties in L1, thus enabling the use of specific FLA profiles (Wen, 2012). This theoretical statement underpins our current research, as we formulated our major hypothesis: there is a difference in language aptitude between the values of pupils from low SES and that of pupils from non-low SES background. We also have to emphasise the regional characteristic of the schools as mentioned above, as Hungary displays a dramatic difference between schools in socially and economically deprived areas and in more balanced or non-deprived areas. Schooling segregation is a severe issue in Hungary; thus we have expected strong findings in our language aptitude research.

The test developed by Kiss (Kiss, 2004) measures the language aptitude of 6th graders in the Hungarian educational system, a category that involves pupils aged 12 . Our research included pupils between the ages 11-13, as grade 6, especially in less-populated villages, in socially deprived regions often composes pupils in this age range (11-13). The instructions of the test are in Hungarian, and it does not aim to measure or evaluate the foreign language knowledge of the children, but it examines plausible difficulties in their language skills. The structure of the test strictly follows that of Carroll's as it comprises four major areas of language skills and competencies.

Task 1 is a listening-based exercise, which checks the phonetic coding ability. It consists of 15 items, all of them with 4 multiple choice options. The language of the task is artificial. The pupil hears the four options, followed by a random combination of words, one of which is part of the four possible options heard only once. The pupils have to listen for the word and recognise it by the phonetic pattern. We can clearly formulate the deduction that the difference between students from severely deprived background and students from non-deprived background was miniscule. Around 
the age of 12, listening skills and phonetic decoding abilities are quite similar and intact regardless of the socio-cultural, educational, family and schooling background.

Task 2 is in Hungarian, the native language of the participants. It is based on Carroll's grammar sensitivity task. As we had previously expected, there proved to be significant differences between the two groups. The task consists of 10 items, where the pupils have to recognise and identify the same function of one word (eg. subject, verb, object etc) in another sentence. For example: LONDON is the capital of England. (sentence 1) - The family likes going fishing. (sentence 2). The pupil is expected to identify the same form of speech and function of the word in capital letter in the second sentence as well (London=family). Understanding grammar, or just even the simple instruction was a challenging task for many students in disadvantaged background. The task posed difficulties to children in the control-group as well, yet they seem to display more adequate coping and strategic skill. The task cannot be considered difficult as it is clearly formulated, well-structured and logical. However, many children from disadvantaged background were struggling to comprehend the task or the logic of the sentences. This would lead us to the significance and importance of L1, and what is regarded as an outstanding issue in Hungary: native language competency.

Task 3 is a predominantly inductive logical one. This exercise also operates with an unknown language, in the Hungarian version of the language aptitude test, it is an African language. Participants have to realise and understand grammatical rules in a language unknown to them, by applying inductive way of thinking with the help of a mini vocabulary set. The task is grammarcentred, heavily employing translational skills. For example: dant $=$ hundred, oko $=$ brown, bur $=$ table, then using this given information students have to match possible translation to basic sentences. This task usually causes opposition according to students' declarations: they formulate their fear, their struggles and even their lack of understanding of the rules. This is the most timeconsuming task, even though it consists of only 11 items (with 4 multiple choice options). Once pupils understand the logic of the task itself, then they easily achieve maximum score on it, however they often tend to spend a lot of time on working out the rules and the logic. This task is probably the most time consuming to students in poorer regions and schools, as they apparently are not used to working through such complex and long tasks.

Task 4 is a simply mechanic rote-learning exercise, where pupils are expected to memorize 10 words, in Suaheli language and their Hungarian meanings (eg. tamba=lion). Students have 3 minutes to examine the first sheet of pair of words, while they are also instructed to rote-learn the words. This is followed by another unit of 3 minutes, when they can test their knowledge practise the pairs by writing the Hungarian meaning on the second sheet, where they only have the words in the unknown language. (tamba $=\ldots \ldots$...). This second slot of 3 minutes for writing the words down is one of the most effective tasks among pupils in disadvantaged areas. They seem to adore the task of practice by copying, they tend to work in the deepest silence with great devotion. Most pupils (both deprived and non-deprived) have difficulties to use up the first slot of 3 minutes to rote-learn the new lexical items: they fidgeted, got bored or chatty. It was apparent that rote-learning is de-facto a challenging task for them and could not learn 10 randomly selected pair of words without any context. Despite obvious struggles in both types of participants, the most significant difference was to be seen - as expected - in this last task connected to working memory. During our discussion of the findings, we will point out that the methodological implications presuppose a plausible intervention in enhancing working memory as well as providing improved and individual learning strategies for pupils in deprived background.

\section{The Research: introducing the setting}

The pilot study into language aptitude was conducted in 2018 in Eastern-Hungary in severely deprived regions, known as low SES schools, as well as in the capital, Budapest, one disadvantaged school. The control-group was a highly selective school in a big city, which also serves as the centre for teacher training, furthermore this school has no disadvantaged pupils in grade 5-6. The number of participants was 175 ( $\mathrm{N}=175)$, most of them aged 11-12. Respectively, the distribution of the students was the following regarding number and the proportion of low socio-economic status. Socio-economic status is 
annotated in the official school register, supervised by the school-secretary and it follows the Hungarian categories and abbreviations: $\mathrm{H}=$ deprived situation, $\mathrm{HH}=$ profoundly deprived situation (eg. extremely low SES added to severe family issues, like living with foster-parents, or parents are imprisoned, or orphans taken care of by elder siblings. Our research does not differentiate between low and profoundly low SES or deprived and profoundly deprived background. We used the proportions of low SES pupils officially reported by the schools. It has to be noted however, that the actual number of pupils officially living under deprived circumstances must be higher.

Introducing the setting of the research:

School 1 (HB1) included 65 pupils, low SES: 0 - 1\%

School 2 (BP) included 60 pupils, low SES: 13\%

School 3 (HB2) included 42 pupils, low SES: $43 \%$

School 4 (HB3) included 31 pupils, low SES: 84\%

\subsection{Data and Findings}

The final score of the language aptitude test was 45 points, the best result was 43 points. The test was taken under the same circumstances, as pupils had 45 minutes - 1 lesson - to complete all the tasks. Our findings show that while pupils from non-deprived and deprived areas had hardly any different results at certain tasks, there are significant differences at some. A closer look at the data of the preliminary study could already refer to methodological implications, which will be discussed in the final part of the paper.

\subsection{Our findings:}

Following general patterns in language aptitude studies, the difference between the sexes complied with the findings of several studies: girls usually outscore boys in language aptitude.

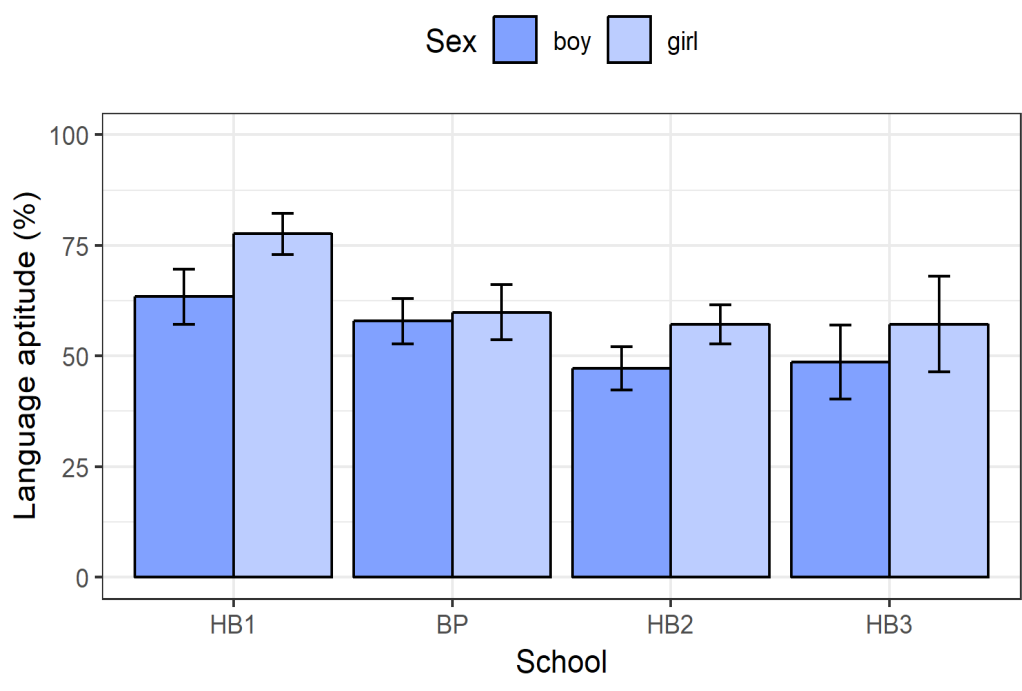

Figure 1. The difference in language aptitude total score between sexes

As in many studies on language aptitude, girls achieve higher score regardless of the socio-economic status. The difference is somewhat smaller in low SES schools, but it can be stated that girls dominantly perform better at language aptitude tests, as it can be observed in Figure 1 as well. 


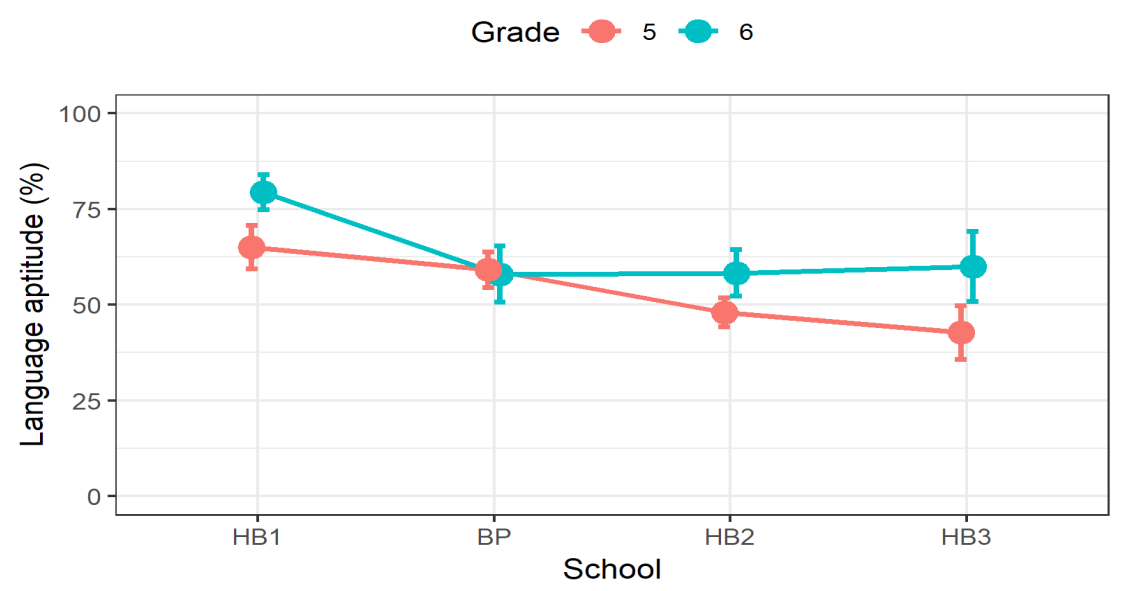

Figure 2. Overall language attitude score in Grade 5 and 6

The overall result of our pilot examination highlights the differences between the participating schools. The school from the non-deprived background (HB1) has a remarkably higher score in both grades, but in grade 6 it is even more significant. Pupils from low SES environment score lower and almost in the same range. What is also outstanding as a part of our findings is that pupils in grade 6 from the nondeprived background overdo their peers. The lowest general score was achieved by fifth graders in School HB3, which has the highest proportion of low SES pupils. We do hope that our findings will highlight the main differences in the individual tasks as well.

\subsection{Findings: analysing task-based differences in language aptitude test scores}

Following Figure 2 highlighting the general score, we now turn to the analyses of the individual tasks. The tasks follow the structure of the original MLAT test created by Carroll, and it covers listening, reading skills as well as induction of grammar and working memory. In our research we expected that there would be differences among the students according to their socio-economic status: the lower SES can lead to lower language aptitude value. Pupils in low social-economic status have parents with lower parental educational background, which respectively can result in reading less to children, diminished set of vocabulary and underdeveloped language skills. As we will see from the individual tasks, most of the hypotheses were justified, however, parental education really influences children from non-deprived, higher SES background. The higher parental education children's parents have, the higher language aptitude values they will possess.

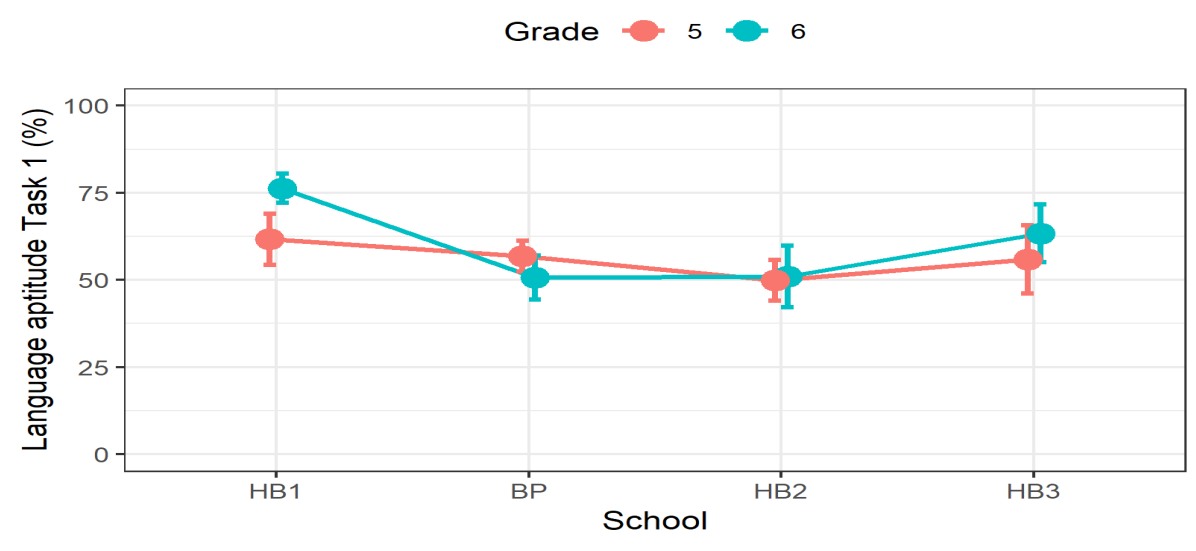

Figure 3. Task 1 - The phonetic coding.

This task covers the listening skills of foreign language acquisition. It includes 15 items in an artificial language, and pupils are expected be able to recognise the sound patterns of these unknown words. Surprisingly, this task was not only the most enjoyable fun activity among 5th and 6th graders, but this was the one where the difference in socio-economic status mattered the least. Apart from the non-low 
SES 6th graders, there is basically no difference between the groups and ages. It is even outstandingly remarkable that the pupils from the most deprived school scored nearly as high as the non-deprived pupils. It is also important to mention that there is hardly any difference in the score among 5th graders. The explanation may lie in the fact that listening abilities are innate, at this age (10-12) socio-economic status plays hardly any role regarding this skill. The participants from low SES schools involved several ethnic minority members, mainly from Roma origin, with pupils growing up in bilingual or close tobilingual families and culture.

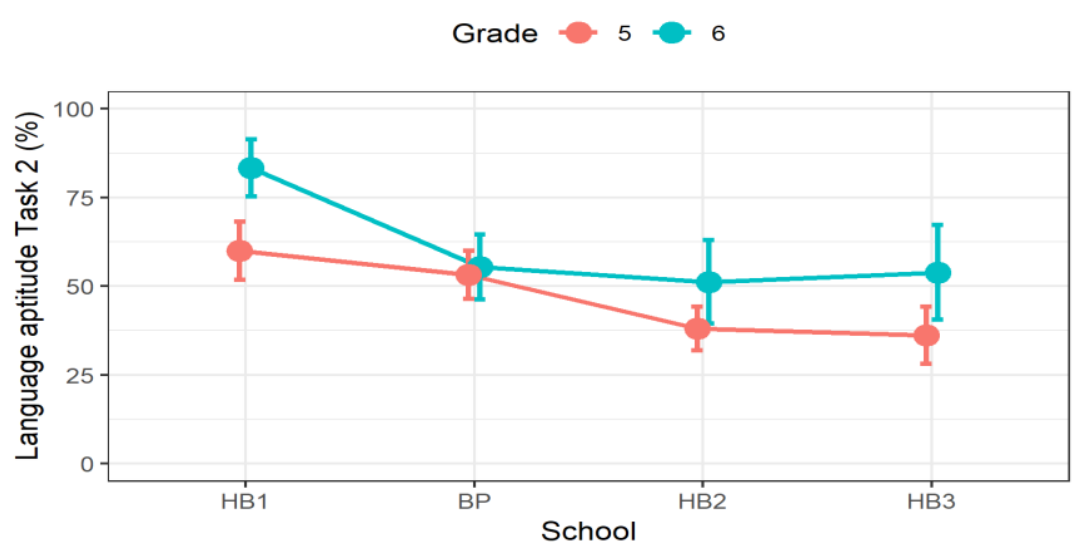

Figure 4. Task 2 - Grammatical sensitivity

Task 2 focuses on the understanding of the grammatical rules in one's own native language. Figure 4 displays the results of this task, which is usually the only monolingual task in a language aptitude test. This examines the grammar sensitivity in one's language, in our case in Hungarian. The task sets out to analyse the grammatical awareness of the pupils, whether they can identify the various forms of speech and syntactical function of parts in a pair of Hungarian sentences, for instance: a transitive object is underlined, and the pupils need to identify the same function in the other sentence, that is another transitive object. For Hungarians conjugation and suffixes often facilitate this task, yet the difference between the two major social-economic school environment seems to be substantial. Both 6th graders and 5th graders achieve better at this task than their own peers, however we have to admit that the 6th graders in School 1 (HB1) have reached a significantly higher score. We presume that it can be explained by the difference in socio-economic status, as pupils with higher parental education grow up among more books, acquire a higher set of vocabulary, are talked to more, which can easily lead to an increased awareness and understanding of grammatical rules.

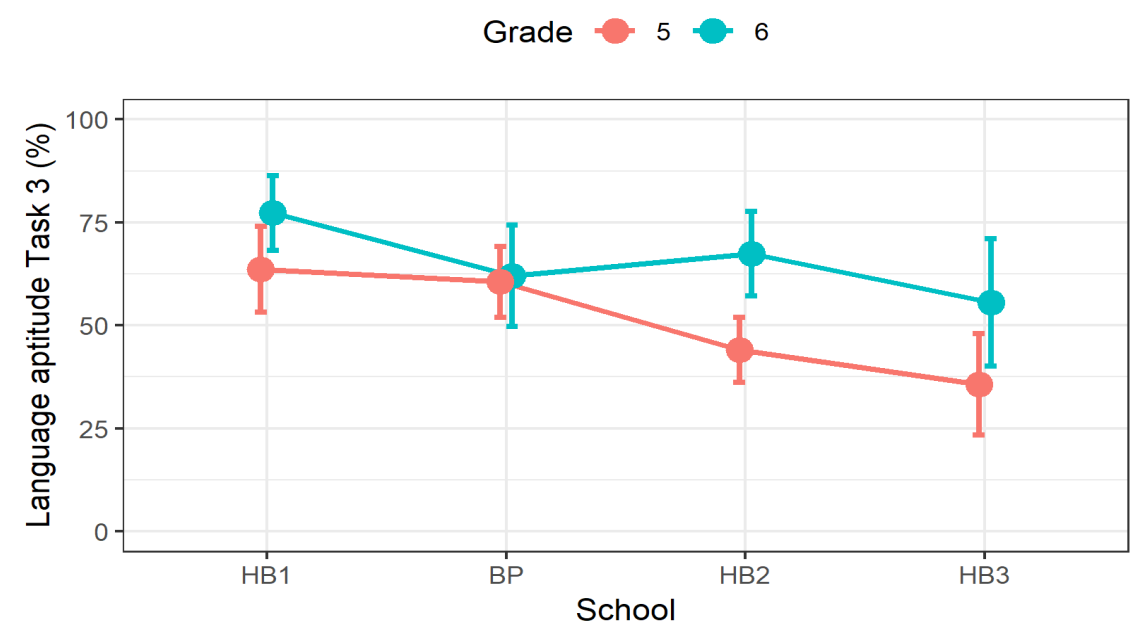

Figure 4. Task 3 - Inductive cognitive abilities 
Task 3 examines inductive cognitive abilities. Here pupils are required to work with an unknown language, in the Hungarian version of the language aptitude test, it is an African language. Participants need to recognise and understand grammatical rules, then they are expected to apply these with inductive way of thinking. The task is grammar-centred, profoundly employing translational skills. For example: dant $=$ hundred, oko=brown, bur= table, then using this given information students have to match possible translation to basic sentences. This is the only task that brings about general opposition among pupils: misunderstanding the instruction, the tasks or the rules is very common. This task appears to be the most challenging to students from deprived background, as they apparently are not used to working through such complex and long tasks. The table shows that 5th graders do underachieve in this task, particularly HB2 and HB3 schools with the highest proportion of low SES pupils. Intriguingly, the difference is not significant among 6th graders, thus we cannot state that there is a correlation between low socio-economic statues and inductive thinking among 6th graders. School HB1 (almost zero low SES) and school HB3 (very high number of low SES pupils) display fairly similar scores, which promotes the conclusion that inductive abilities can be improved and stimulated.

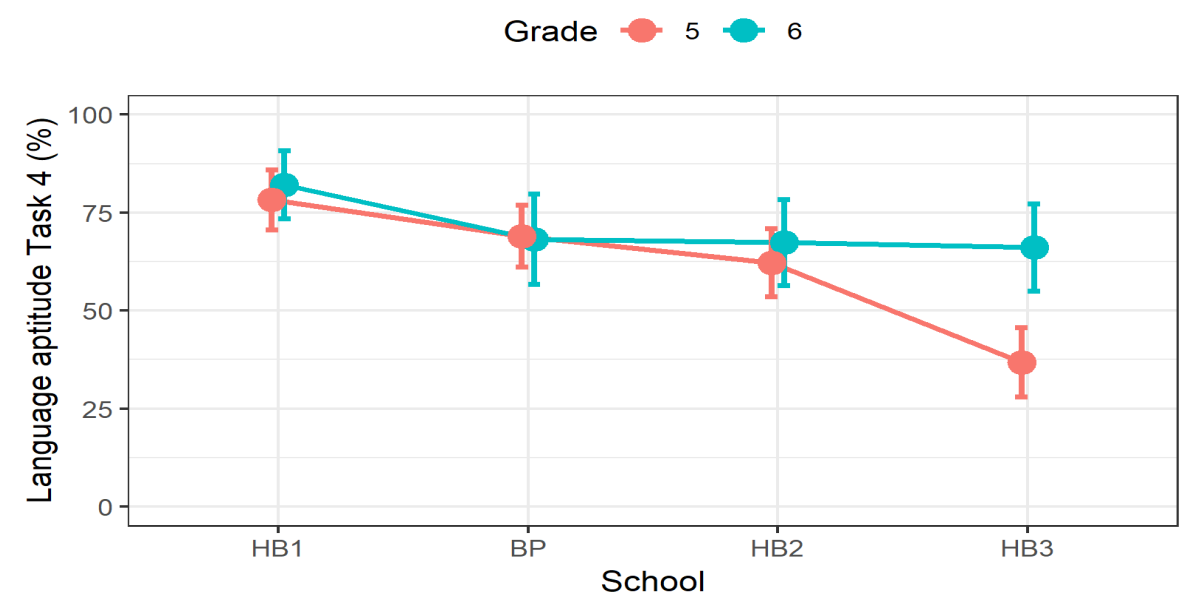

Figure 5. Task 4 - Work-memory based exercise

Rote-learning lexical items is the focus of Task 4, which is predominantly a work-memory based exercise. In our hypothesis 5 we expected to receive differences in this particular task, but the substantially underachieving 5th graders from School HB3 (with the highest number of low SES pupils) are far from our expectations. Task 4 sets out to examine rote-learning and lexis-learning strategies of the participants. Pupils are asked to learn 10 pairs of words, in Hungarian and the matching meaning in Suaheli, most of which are very simple, everyday lexical items. They have 3 minutes to study the words, then another 3 minutes to practise and copy on a worksheet. When the 6 minutes have passed, pupils have to do a multiple-choice based vocabulary test of 10 items. The task is challenging as there is no context and the words are randomly selected. Most pupils from low SES background and schools displayed severe difficulties to get engaged in this task, furthermore they often had failing learning strategies or completely lacking those. Pupils found it extremely hard to focus and keep up their attention for 6 minutes $(3+3)$, and they could not make use of the study and the subsequent practice time. When it came to copying the word-pairs on a separate worksheet as part of the practice time, they became more engaged in the task, but most of them considered it daunting, tedious and extremely difficult. It was a common argument that "I don't know how to learn these words".

\section{Conclusion}

This paper has described a study exploring the language aptitude scores of pupils from deprived background, particularly from low socio-economic background in Hungary. We have conducted a comparative study of language aptitude as the control-group was a school with almost $0 \%$ of low-SES pupils and the majority of the pupils in the examination were from deprived and profoundly low socioeconomic background. We examined the overall scores of the pupils, as well as the results of the 
individual tasks. A framework for setting and context was provided with regional characteristics of low socio-economic environment in Hungary. Following this, the term of language aptitude was detailed, and our testing tool was introduced. It has become evident that in some components of language aptitude, such as phonetic coding or inductive thinking there is no significant difference between various socioeconomic backgrounds, thus we can claim that socioeconomic factors do matter when it comes to grammar sensitivity in one's native language and in rote learning/work memory tasks. Our preliminary data and findings help us understand the importance of emphasizing individual needs in any classroom context, particularly in deprived schools and among pupils from low socio-economic background, since this may be the only key to effective and successful language teaching there.

\section{Note}

This study was funded by the Content Pedagogy Research Program of the Hungarian Academy of Sciences.

\section{Bibliography}

Carroll, J. B. (1962): The prediction of success in intensive foreign language training. In Robert Glaser (Ed.), Training research in education. University of Pittsburgh Press, Pittsburgh, PA. 87-136.

Carroll, J. B. (1981): Twenty-five years of research on foreign language aptitude. In K. Diller (Ed.), Individual differences and universals in language learning aptitude. Newbury House, Rowley, MA. 83118.

Colhoun, H. M., Hemingway, H. \& Poulter, N. (1998): Socio-economic status and blood pressure: An overview analysis. Journal of Human Hypertension, 12. 91-110.

DeCarlo Santiago, C., Wadsworth, M. E. \& Stump, J. (2011): Socioeconomic status, neighbourhood disadvantage, and poverty-related stress: Prospective effects on psychological syndromes among diverse low-income families. Journal of Economic Psychology, 32. 218-230.

Geske, A. \& Grinfelds, A. (2012): Family Background and Effects on Learning. In: Seel N.M. (eds.) Encyclopedia of the Sciences of Learning. Springer, Boston, MA.

Howard, K. S., Carlstrom, A. H., Katz, A. D., Chew, A., Chew, R. G., Christopher, L. L. \& Caulum, D. (2011): Career aspirations of youth: Untangling race/ethnicity, SES, and gender. Journal of Vocational Behavior 79, 98-109.

Kertesi, G. \& Kézdi, G. (2009): Általános iskolai szegregáció Magyarországon az ezredforduló után. Közgazdasági Szemle, 56 (11), 959-1000.

Kim, Y., Sherraden M. \& Clancy, M. (2013): Do mothers' educational expectations differ by race and ethnicity, or socioeconomic status? Economics of Education Review, 33, 82-94. doi.org/10.1016/j.econedurev.2012.09.007

Kiss, Cs. (2004): Factors affecting Hungarian young learners' success in English language learning, Ph.D. Dissertation, University of Pécs

Lannert, J. (2003): A továbbtanulási aspirációk társadalmi meghatározottsága. In Lannert, Judit (szerk.): Hogyan tovább? Pályaválasztási elképzelések Magyarországon. Országos Közoktatási Intézet, Budapest.

Molnar, B., Cerda, M., Roberts, A. L., \& Buka, S. (2008): Effects of neighborhood resources on aggressive and delinquent behaviors among urban youths. American Journal of Public Health, 98, 10861093.

Newacheck, P., Hung, Y. Y., Park, M. J., Brindis, C., \& Irwin, Ch. E. (2003): Disparities in adolescent health and health care: Does socioeconomic status matter? Health Services Research, 38, 1235-1252. 
OECD, 2016. "Performance differences between and within schools explained by students' and schools' socio-economic profile", in PISA 2015 Results (Volume I): Excellence and Equity in Education, PISA, OECD Publishing, Paris.

Russell, G., Ford, T., Russell, A. E. \& Williams, R. (2016): The association between socioeconomic disadvantage and attention deficit/hyperactivity disorder (ADHD): A systematic review. Child Psychiatry and Human Development, 47, 440-458.

Spencer, M. S., Kohn, L. P. \& Woods J. R. (2002): Labeling vs. early identification: The dilemma of mental health services under-utilization among low-income African American children. African American Perspectives, 8, 1-14.

Steptoe, A. \& Marmot, M. (2004): Socioeconomic status and coronary heart disease: A psychobiological perspective. In L. J. Waite (Ed.), Aging, health and public policy: Demographic and economic perspectives. Population Council, New York, NY. 133-152.

Zhang, M. (2003): Links between school absenteeism and child poverty. Pastoral Care in Education, 21, 10-17.

Wen, Z. (2012): Working memory and second language learning. International Journal of Applied Linguistics, 22 (1), 1-22.

\section{Authors}

Fruzsina Szabó, Institute of English and American Studies, University of Debrecen, Debrecen (Hungary). E-mail: szabo.fruzsina@arts.unideb.hu

Tünde Polonyi. Institute of Psychology, University of Debrecen, Debrecen (Hungary). E-mail: tundepolonyi@gmail.com

Kálmán Abari, Institute of Psychology, University of Debrecen, Debrecen (Hungary). E-mail: abari.kalman@gmail.com 